\title{
Ladybird (Coleoptera: Coccinellidae) dispersal in experimental fragmented alfalfa landscapes
}

\author{
AudRey A. GREZ ${ }^{1}$, TANIA ZAVIEZO² and MARTA RÍOS ${ }^{1}$ \\ ${ }^{1}$ Facultad de Ciencias Veterinarias y Pecuarias, Universidad de Chile, Casilla 2 Correo 15, La Granja, Santiago, Chile; \\ e-mail: agrez@uchile.cl \\ ${ }^{2}$ Facultad de Agronomía e Ingeniería Forestal, Pontificia Universidad Católica de Chile, Casilla 306-22, Santiago, Chile; \\ e-mail: tzaviezo@puc.cl
}

Key words. Dispersal, fragmented landscapes, distance between fragments, mark-recapture experiments, ladybird, Eriopis connexa

\begin{abstract}
Habitat fragmentation may affect the dispersal behaviour of individuals across the landscape. If there is a high boundary contrast between the remaining fragments and the matrix, individuals should tend to stay inside the fragments, but the configuration of the landscape, i.e. the level of fragmentation and isolation distance between fragments, may modulate this. To test these ideas, we made several mark-recapture experiments with the ladybird Eriopis connexa (Germ.) in manipulated alfalfa model landscapes $(30 \times$ $30 \mathrm{~m}$ ). Specifically we evaluated (i) ladybird movement and permanence in alfalfa and bare ground areas, (ii) how they move across fragment/matrix boundaries, (iii) how their movement between fragments within a landscape is affected by fragmentation level and isolation distance, and (iv) how their permanence in the landscape is affected by fragmentation level and isolation distance. The fragmented alfalfa landscapes had a constant level of habitat loss (84\%), but varied in the level of habitat fragmentation (4 or 16 fragments), and isolation distance between fragments $(2$ or $6 \mathrm{~m})$. We also sampled aphid abundance in the different landscapes through time. We found that ladybirds stay longer and displace less in alfalfa than on bare ground, and that they move less from the alfalfa fragments to the neighbouring bare ground matrix than vice versa. At the landscape level, ladybirds had a higher inter-fragment movement when fragments were closer, they tended to remain in less fragmented landscapes, regardless of their isolation distance. Aphid abundance increased in time, but it was similar in all landscapes. Ladybird movement within fragments, in the matrix and in the boundary between both habitats explains why ladybirds concentrate within alfalfa fragments. However, their dispersal movements at the landscape level do not reflect the higher abundance sometimes found for several species of ladybirds in more fragmented landscapes. At this larger scale, other mechanisms may have a stronger influence in determining the abundance of ladybirds.
\end{abstract}

\section{INTRODUCTION}

A landscape is a heterogeneous area of land, containing habitat patches of different kinds, arranged in a particular configuration. A landscape should not be a priori restricted to certain spatial scale, rather it should be defined by the scale relevant to organisms and the phenomenon under consideration (Wiens, 1992; Ims, 1995).

Dispersal or the movement of organisms across the landscape is an important process in population biology (Bullock et al., 2002; Schtickzelle \& Baguette, 2003). Movement can be very complex and can occur at various hierarchical spatial scales for different activities. For example, foraging and mate-finding will usually occur at small spatial scales, probably within the same habitat, while searching for new habitats, and migration between regions or towards hibernation sites, occur at larger scales (Ims, 1995). The movement decisions at one level may be affected by spatial structures at levels below and above in the hierarchy (Kotliar \& Wiens, 1990).

Fragmentation occurs when a continuous area of habitat is transformed into a number of smaller patches with smaller total area, isolated from each other by a matrix of habitat unlike the original (Fahrig, 2003). As a result, new boundaries between habitats are created. If there is a high boundary contrast between the remaining fragments and the matrix, individuals should tend to stay inside the frag- ments, but the configuration of the landscape, i.e. the level of fragmentation and isolation distance between fragments, may modulate this (Collinge \& Palmer, 2002; Morales, 2002). For example, in more fragmented landscapes, insects may have a higher emigration rate from the remaining smaller habitat fragments because encounters with boundaries are more frequent. This may result in a lower permanence of individuals in those fragments compared to larger ones. But emigration rates may also be low if there is a high risk of mortality in a hostile matrix (Fagan et al., 1999; Fahrig, 2001; Mennechez et al., 2003). Also, if habitat fragments in a landscape are close, in relation to the movement capability of the organisms, emigrating individuals from one fragment may have a high probability of settling on another fragment within the landscape (Matter, 1996). This may result in a higher permanence of individuals in landscapes with less isolated fragments.

Ladybirds (Coleoptera: Coccinellidae) are affected by habitat fragmentation through changes in their movement patterns across the landscape. Since ladybirds are important natural enemies of aphids (Dixon, 2000), the effects of agroecosystem fragmentation on their dispersal behaviour may compromise their efficacy as biological control agents (With et al., 2002). For instance, Coccinella septempunctata L. delays its colonisation in experimentally 
fragmented goldenrod patches, resulting in local outbreaks of its prey, the aphid Uroleucon nigrotuberculatum (Olive) (Kareiva, 1987, 1990).

Eriopis connexa (Germ.), a species endemic to southern South America (Hofmann, 1970), varies in abundance depending on vegetation attributes. For example, this species is more abundant in broccoli patches with a low perimeter-to-area ratio due to low emigration rates from these patches (Grez \& Prado, 2000). In experimentally fragmented alfalfa landscapes, we found that $E$. connexa, and other ladybird species, concentrates inside alfalfa fragments surrounded by a bare ground matrix, and were positively affected by the level of habitat fragmentation. Nevertheless, this positive effect was transient and, for $E$. connexa, it was only detected when surveying intensively the whole landscape (Zaviezo, Grez \& Pérez, in prep.). At high levels of habitat loss (i.e., 16\% remains of initial habitat), ladybirds were more abundant in fragmented alfalfa landscapes constituted by 16 fragments, particularly when fragments were close together, than in those with the same remaining alfalfa habitat distributed in only four larger fragments (Grez et al., 2004).

Because ladybird dispersal behaviour could explain these abundance patterns, we studied, in the same experimental landscapes, the movement of adult E. connexa at three spatial scales (i.e., within habitats, at fragmentmatrix boundaries and at landscape scales). First, we recorded the movement and permanence (i.e., time remaining in a habitat) of ladybirds in alfalfa patches and in bare ground; second, we determined ladybird movement from fragment to matrix and vice versa; third, we analysed their movement between fragments in landscapes that vary in fragmentation level and isolation distance; and fourth, we compared the permanence of ladybirds in landscapes that vary in fragmentation level and isolation distance.

\section{MATERIAL AND METHODS}

\section{Experimental landscapes}

Our field research was conducted at University of Chile

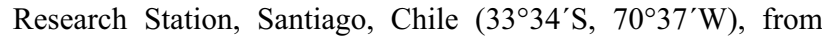
December 2002 to March 2003. We created an experimental model system composed of 12 landscapes $30 \times 30 \mathrm{~m}$ (3 repli- cates of 4 types) of alfalfa varying in levels of fragmentation and isolation distance between fragments: (a) 4-2 $\mathrm{m}$ (four $36 \mathrm{~m}^{2}$ fragments separated by $2 \mathrm{~m}$ ), (b) $4-6 \mathrm{~m}$ (four $36 \mathrm{~m}^{2}$ fragments separated by $6 \mathrm{~m})$, (c) $16-2 \mathrm{~m}\left(169 \mathrm{~m}^{2}\right.$ fragments separated by $2 \mathrm{~m}$ ), and (d) 16-6 m (16 $9 \mathrm{~m}^{2}$ fragments separated by $\left.6 \mathrm{~m}\right)$ (Fig. 1). In these landscapes, $84 \%$ of the original habitat was removed, an amount of habitat loss above the threshold suggested to negatively affect the search success of many insects (Wiens et al., 1997; With \& King, 1999; With et al., 1999, 2002). The matrix surrounding the fragments was bare ground, and the area surrounding the landscapes was composed of annual grasses that were kept short and dry, with no irrigation. For some experiments we also used a $30 \times 30 \mathrm{~m}$ unfragmented alfalfa patch and an equivalent area of bare ground. The scale of these experimental landscapes $(30 \times 30 \mathrm{~m})$ is adequate for studying the dispersal behaviour of ladybirds, considering that previous studies have used even smaller spatial scales with significant results (Kareiva, 1987; Ives at al., 1993; Banks, 1999; With et al., 2002).

Alfalfa in all of the landscapes was irrigated every two weeks, and by December 19 reached $90-100 \%$ cover. Alfalfa height, throughout the season, varied from 40 to $70 \mathrm{~cm}$, but did not differ between landscapes. No insecticides were used.

\section{Handling of ladybirds for mark-recapture experiments}

Mark-recapture experiments with E. connexa were carried out during the mornings of sunny days, with average daily maximum and minimum temperatures of $29.5 \pm 0.8^{\circ} \mathrm{C}$ and 12.9 $\pm 0.4^{\circ} \mathrm{C}$, respectively. For all the experiments we marked more than 8700 individuals collected from surrounding alfalfa crops. Coccinellids were marked with acrylic paint (Testor enamel, Rockford, IL), a marking technique successfully used for studying the movement of many insects, ladybirds among them (e.g., Bach, 1980; Turchin, 1987; Ives et al., 1993; Grez \& Prado, 2000). To clearly identify the release location of the individuals, a combination of dots of different colours were painted on the elytra. Recaptures were made with sweep-nets, the most efficient method for collecting coccinellids in alfalfa (Elliott \& Michels, 1997), during the first $24 \mathrm{~h}$, when the highest number of coccinellids are usually recaptured (Ives et al., 1993; Grez, 1997; Grez \& Prado, 2000).

\section{Movement and permanence of ladybirds in continuous alfalfa patches and on the bare ground matrix}

For this experiment we used the unfragmented alfalfa patch and the bare ground patch that were separated by $>150 \mathrm{~m}$. On the centre of each patch we superimposed a grid of 81 cells $(2 \times$ $2 \mathrm{~m}$ ). On December 26, and January 18, in each one of the 25

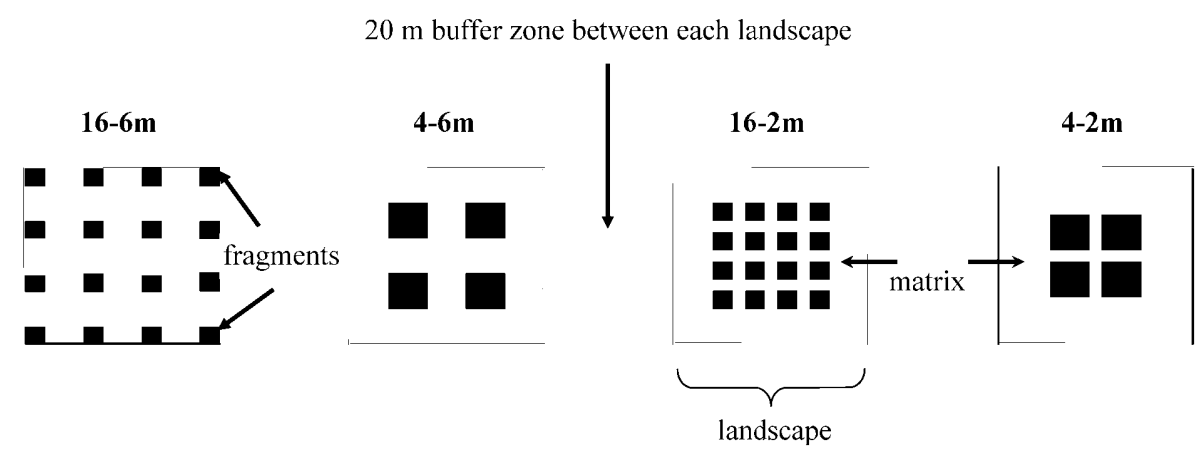

Fig. 1. Experimental landscapes used to study the effect of levels of habitat fragmentation and isolation distance on the dispersal of Eriopis connexa. Each plot $(30 \times 30 \mathrm{~m})$ represents a landscape pattern with two levels of habitat fragmentation $(4$ or 16 fragments), and two levels of isolation distance between fragments ( 2 or $6 \mathrm{~m}$ ). All fragmented landscapes have an $84 \%$ of habitat loss. These four types of landscape were replicated three times in the field. 
central cells, we released 15 marked ladybirds. To determine how the movement of individuals varied through time, we sampled them 1, 2 and $3 \mathrm{~h}$ after their release. In both habitats, we sampled the whole surface of each cell by passing the sweep-net and observing the ground during a constant period of time (1 min per cell). All recaptured individuals were marked with an additional white dot to recognise further recaptures. The number of ladybirds recaptured (i.e., a measurement of permanence), and their net displacement (i.e., straight-line distance of the pathway) between recapture periods were calculated. The distances travelled by ladybirds in alfalfa and matrix were compared using frequency histograms. The histograms were analysed with a Poisson linear model with log link (Generalised linear model), comparing the observed distributions through a Chi-square test. These, and all following statistical analyses, were made using Statistica 5.5 (StatSoft, 2000). For all tests, $P$ $<0.05$ was defined as significant.

\section{Movement of ladybirds across fragment-matrix boundaries}

For this experiment we used six $6 \times 6 \mathrm{~m}$ fragments. On December 18 and January 15 , we simultaneously released 60 marked individuals scattered along one of the fragment edges (1 $\mathrm{m}$ width), and other 60 in the adjacent matrix edge ( $1 \mathrm{~m}$ width). Recaptures were made 1, 2 and $3 \mathrm{~h}$ after release, by observing and passing the sweep-net through the whole fragment (72 sweeps in total), and also through a similar area (i.e., $6 \times 6 \mathrm{~m}$ ) in the matrix. Those captured individuals that moved from one type of habitat to the other were marked with an additional white dot on the pronotum, in order to recognise subsequent movements between habitats. We calculated the percentage of individuals that stayed in the same release habitat (permanence), and also the percentage that moved between habitats. For this and the following experiments, data were arcsine transformed and analysed with repeated measures ANOVAs. Multiple comparisons were made with Tukey's (HSD) test.

\section{Movement of ladybirds between fragments of landscapes} that vary in the level of fragmentation and isolation distance

On December 16, January 9 and March 26, in each landscape we released 160 marked individuals. The insects were scattered in the centre of each fragment, 10 or 40 per fragment depending on the number of fragments per landscape. We released ladybirds synchronically in all landscapes at 9:30 am, and recaptured them after 1, 2 and $24 \mathrm{~h}$. In this experiment, we decided to make a $24 \mathrm{~h}$ recapture to give more time for ladybird movement between fragments. From these data we calculated the percentage of individuals (over the total released) that moved between fragments, for each recapture period in each date.

\section{Permanence of ladybirds in fragmented landscapes}

Using the data from the inter-fragment movement experiment described above, we estimated the permanence in the landscape, as the percentage of recaptured individuals over the total released. Note that this is an estimate of ladybird permanence at the landscape level, independent of their movement between fragments within the same landscape.

\section{Aphid abundance}

Because aphid abundance could influence the movement behaviour of ladybirds, from December to March, we sampled aphids by passing the sweep-net in the alfalfa in four different sampling points in each landscape.

\section{RESULTS}

\section{Permanence and movement of ladybirds in continuous alfalfa patches and on bare ground}

In general, more beetles were recaptured during the first recapture period (Fig. 2). More individuals were recaptured on the bare ground than in the alfalfa one hour after release (both December and January). This pattern began to reverse in the second recapture period, ending with three times more individuals in the alfalfa patch than on the bare ground (Fig. 2).

Regarding movement patterns in both habitats, statistical analysis of the frequency histograms showed that the ladybirds moved more on the bare ground than in the alfalfa (Habitat effect), dispersed more during the second and third hour after release (Recapture period effect), and increased their movement in time only in alfalfa (Habitat * Recapture period effect) (Fig. 2, Table 1).

\section{Movement of ladybirds across fragment-matrix boundaries}

In all recapture periods and on both dates, a much higher percentage of individuals moved from the bare ground matrix to the alfalfa fragments than vice versa (Habitat effect: $\mathrm{F}_{(1,20)}=46.93, P<0.001$ ). Overall, the percentage of individuals released in the alfalfa that moved to the matrix varied between 0 and $0.6 \%$, with this type of movement not detected three hours after release, yet there was no significant effect of recapture period $\left(\mathrm{F}_{(2,40)}=1.03, P=0.37\right)$. On the other hand, the percentage of individuals released in the matrix that moved to the alfalfa fragments varied between 1.1 and $4.2 \%$ (Table 2 ).

Additionally, a consistently higher percentage of beetles stayed in the alfalfa than in the bare ground matrix (Habitat effect: $\mathrm{F}_{(1,20)}=35.76, P<0.001$ ), and a higher percentage of ladybirds were recaptured in the first period (Recapture period effect: $\mathrm{F}_{(2,40)}=34.76, P<0.001$ ) (Table 2).

TABLE 1. Results of the statistical analysis (Poisson linear model with log-link) for the frequency histograms for the recorded distances travelled by ladybirds after one, two and three hours in alfalfa and bare ground, during December 2002 and January 2003.

\begin{tabular}{lcccc}
\hline & Df & Log-Likelihood & $\chi^{2}$ & $p$ \\
\hline Date & 1 & -722.02 & 2.21 & 0.14 \\
Habitat & 1 & -674.39 & 95.25 & $<0.001$ \\
Recapture period & 2 & -655.95 & 36.87 & $<0.001$ \\
Date * Habitat & 1 & -633.08 & 45.75 & $<0.001$ \\
Date * Recapture period & 2 & -632.94 & 0.28 & 0.87 \\
Habitat * Recapture period & 2 & -608.79 & 48.32 & $<0.001$ \\
Date * Habitat * Recapture period & 2 & -606.82 & 3.93 & 0.14 \\
\hline
\end{tabular}



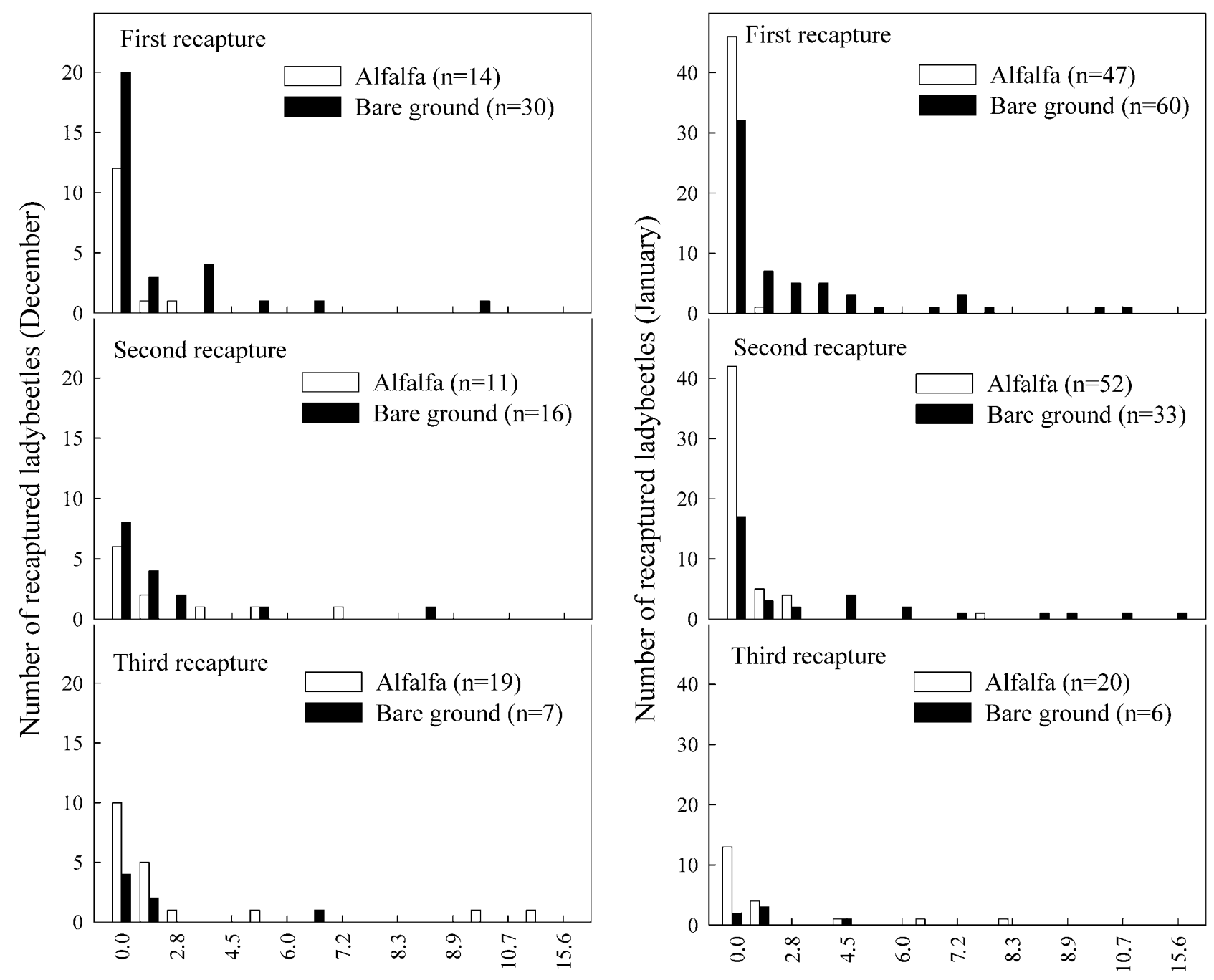

Distance moved (m)

Fig. 2. Frequency histograms of the distances travelled by adult $E$. connexa recorded one, two, and three hours after their release in alfalfa patches and in the matrix (bare ground) during December 2002 and January 2003. $n$ is the number of recaptured beetles out of 375 beetles released per plot. Note the different scales between months.

Movement of ladybirds between fragments of landscapes that vary in the level of fragmentation and isolation distance

Overall, individuals significantly moved more between fragments in landscapes where fragments were close together $(2 \mathrm{~m})$ than in landscapes with fragments further apart $(6 \mathrm{~m})$ (Isolation effect, $\left.\mathrm{F}_{(1,24)}=7.95, P=0.01\right)$, but this kind of movement was not affected by the level of landscape fragmentation (Fragmentation effect, $F_{(1,24)}=$ 2.77, $P=0.11$, Fig. 3). The movement of ladybirds

TABLE 2. Percentage (mean $\pm 1 \mathrm{SE}, \mathrm{n}=6$ ) of recaptured individuals that moved between habitats and percentage of individuals (over the total number of individuals released, $\mathrm{n}=60$ ) that stay in the same habitat.

\begin{tabular}{ccccc}
\hline & \multicolumn{2}{c}{ Move between habitats, across the border } & \multicolumn{2}{c}{ Stay in the habitat where released } \\
\cline { 2 - 5 } December & Alfalfa to Matrix & Matrix to Alfalfa & Alfalfa & Matrix \\
$1 \mathrm{~h}$ & $0.3 \pm 0.3$ & & & $7.5 \pm 3.0$ \\
$2 \mathrm{~h}$ & $0.6 \pm 0.4$ & $1.1 \pm 0.6$ & $13.1 \pm 1.8$ & $0.8 \pm 0.8$ \\
$3 \mathrm{~h}$ & 0 & $3.4 \pm 0.9$ & $4.2 \pm 0.6$ & $1.7 \pm 0.6$ \\
January & & & $6.1 \pm 1.3$ & $6.2 \pm 1.2$ \\
$1 \mathrm{~h}$ & $0.3 \pm 0.3$ & $4.0 \pm 1.7$ & $13.4 \pm 2.6$ & $2.0 \pm 1.4$ \\
$2 \mathrm{~h}$ & $0.3 \pm 0.3$ & $2.8 \pm 1.2$ & $10.6 \pm 1.7$ & $1.1 \pm 0.6$ \\
\hline h & 0 & $4.2 \pm 1.8$ & $9.8 \pm 2.0$ & \\
\hline
\end{tabular}




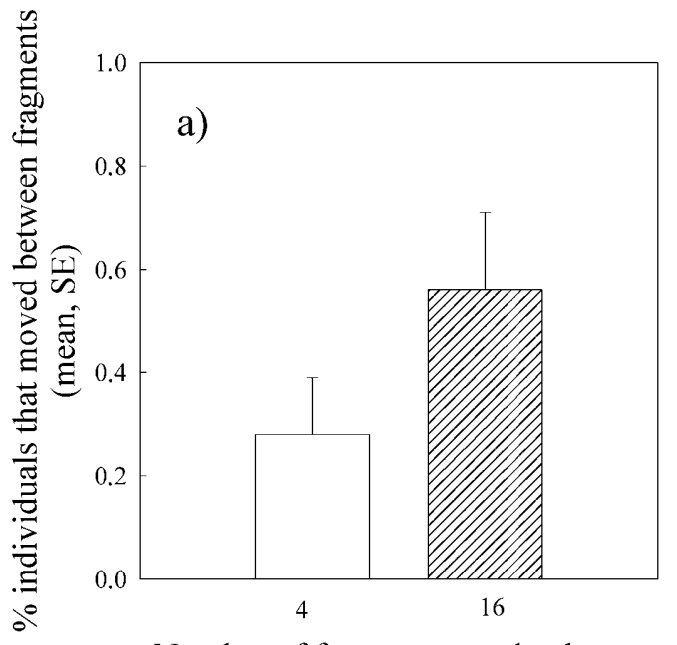

Number of fragments per landscape

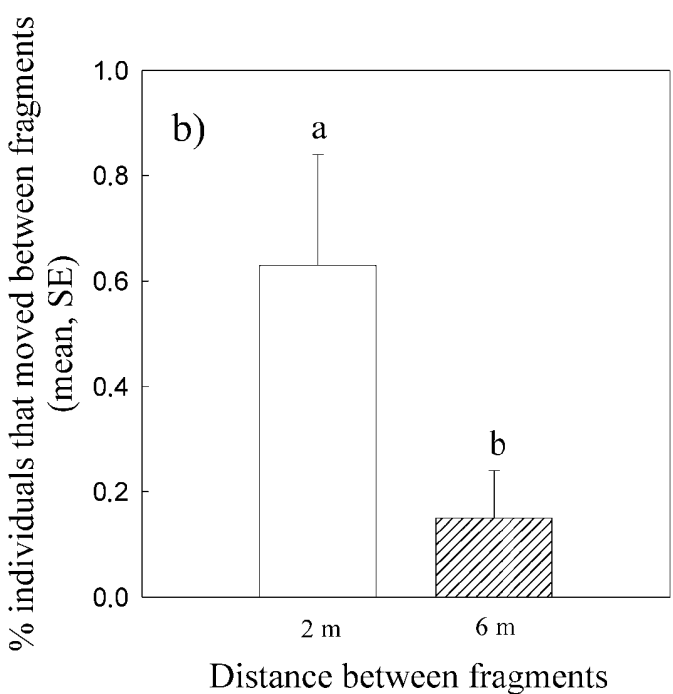

Fig. 3. Overall effects of (a) fragmentation level (4 or 16 fragments), and (b) isolation distance between fragments ( 2 or $6 \mathrm{~m})$ on the inter-fragment movement of $E$. connexa within the same landscape. Letters above bars denote significant differences based on Tukey's test.

between fragments was 2 to 4 times more frequent in the 16-2 $\mathrm{m}$ landscape than in the other landscapes (mean \pm 1 SE, $16-2 \mathrm{~m}: 0.26 \pm 0.08 ; 4-2 \mathrm{~m}: 0.12 \pm 0.04 ; 16-6 \mathrm{~m}$ : $0.07 \pm 0.04 ; 4-6 \mathrm{m:} 0.07 \pm 0.05)$, but there was no significant interaction between fragmentation level and isolation distance $\left(\mathrm{F}_{(1,24)}=1.78, P=0.19\right)$. There was no recapture period effect $\left(\mathrm{F}_{(2,48)}=0.40, P=0.67\right)$.

\section{Permanence of ladybirds in fragmented landscapes}

The permanence of ladybirds in a landscape ranged between 3.8 and $30 \%$, with the highest percentage of beetles recaptured in March. Most recaptures occurred in the first period $\left(\mathrm{F}_{(2,48)}=21.79, P<0.001\right)$, and there was a non-significant trend to recapture more beetles in landscapes with four fragments than in those with 16 (Fragmentation effect, $\left.\mathrm{F}_{(1,24)}=3.82, P=0.06\right)$. Isolation distance between fragments did not affect the permanence

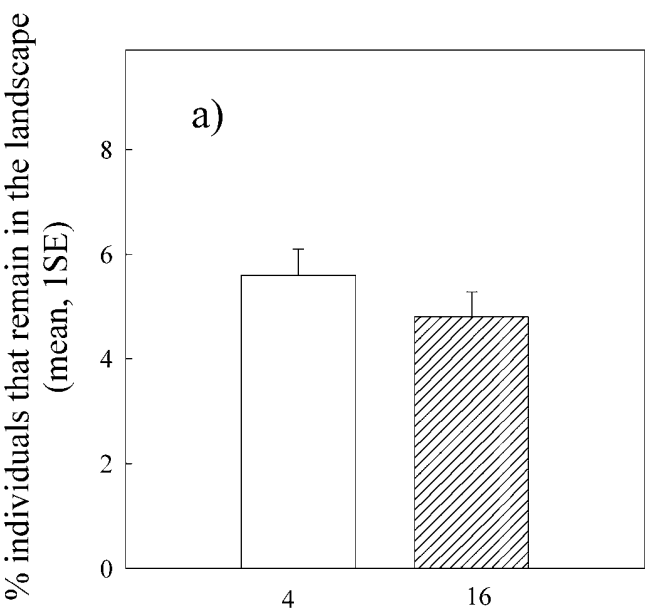

Number of fragments per landscape

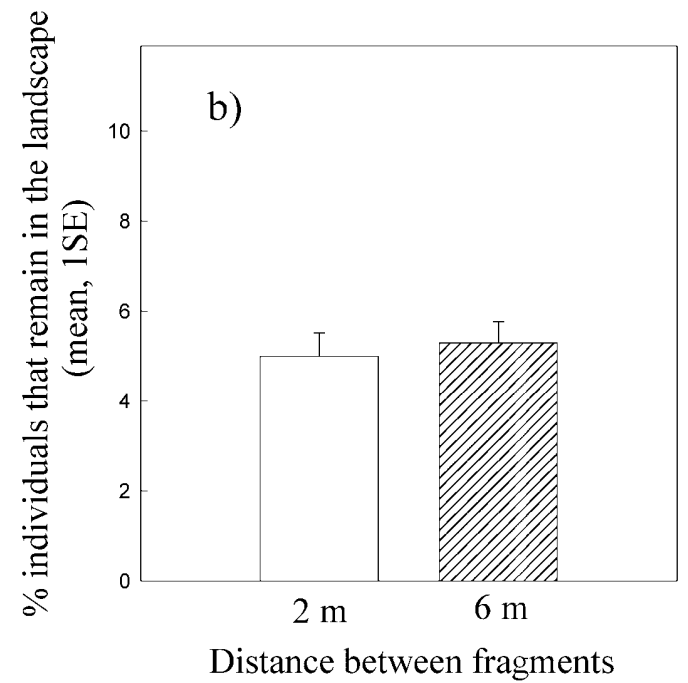

Fig. 4. Overall effects of (a) fragmentation level (4 or 16 fragments), and (b) isolation distance between fragments ( 2 or $6 \mathrm{~m}$ ) on the permanence of E. connexa within the landscape. These data include both individuals that remained in the same fragment and those that moved between fragments within the same landscape.

of ladybirds within a landscape $\left(\mathrm{F}_{(1,24)}=1.72, P=0.20\right)$ (Fig. 4).

\section{Aphid abundance}

Aphid abundance increased over time, with the highest abundance in March (Date effect, $\mathrm{F}_{(6,120)}=8.37, P<$ 0.001). Nevertheless, they were always equally abundant in all landscapes (Landscape effect, $\mathrm{F}_{(3,20)}=0.06, P=$ 0.98, Fig. 5).

\section{DISCUSSION}

Overall recapture rates were low (i.e., $<13 \%$ in each recapture period, and $<30 \%$ when considering all recapture periods), which is a common phenomenon in markrecapture studies using insects, but sufficient enough to detect effects of experimental treatments (Turchin \& 


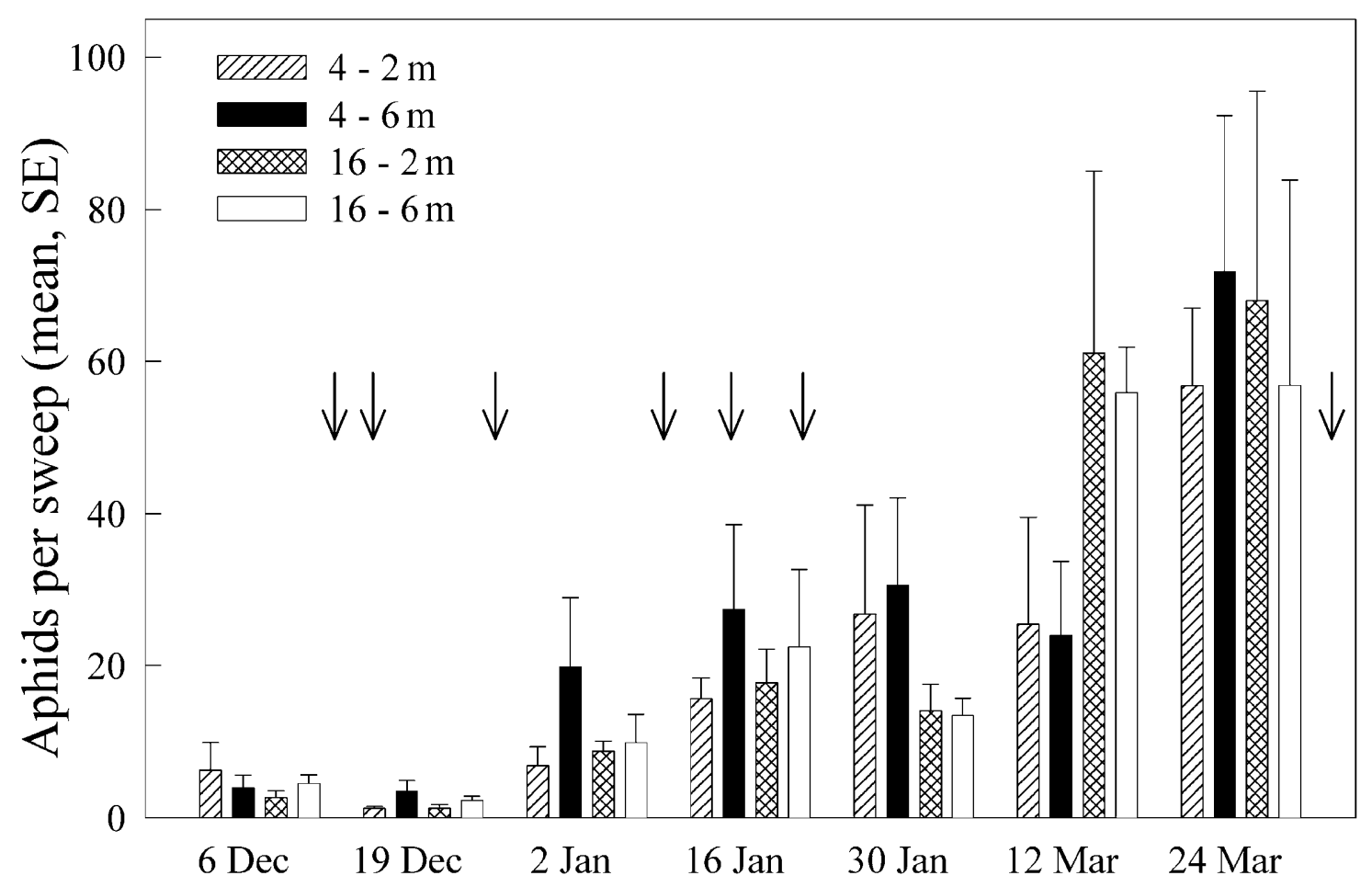

Fig. 5. Aphid abundance through time in fragmented landscapes varying in levels of habitat fragmentation (4 or 16 fragments), and isolation distance between fragments ( 2 or $6 \mathrm{~m}$ ). Arrows denote dates when mark-recapture experiments were carried out.

Thoeny, 1993; Turchin, 1998; Jonsen et al., 2001). The low number of beetles recaptured may be an artifact of the sampling method (i.e., nets do not collect all individuals in an area), but also may indicate that many ladybirds could have rapidly abandoned the landscapes. In fact, it has been described that ladybirds often do not remain long in any given location, but instead appear to move frequently between sites and habitats throughout the breeding season (Evans, 2003). Anyway, our data help develop an understanding of the dispersal behaviour of ladybirds that remain in the landscape, and may be useful for modelling the influence of dispersal on the abundance and distribution of coccinellids in fragmented landscapes (Tischendorf et al., 2005).

Our findings of movement behaviour within habitats and at fragment-matrix boundaries are consistent with the high concentration of ladybirds in the remaining alfalfa fragments. They suggest that when ladybirds arrive to a fragmented alfalfa landscape, if they land in a fragment they stay there, because of their lower displacement and lower probability of crossing boundaries. Alfalfa fragments offer many food resources for ladybirds such as aphids, other small insects, and pollen that make it unnecessary for them to move long distances in search for new resources. Instead, in this type of habitat, they adopt an area-restricted or intensive search behaviour (Dixon, 2000), lowering their probability of reaching the border of the fragment and abandoning it ("slow patches" sensu Morales, 2002). Additionally, even if they reach a border there is a low probability that they will cross it, unless intra and/or inter-specific interactions with competitors or predators, or unknown edge mediated effects promote an earlier departure from the fragment (Doumbia et al., 1998; Fagan et al., 1999; Evans, 2003).

On the other hand, if ladybirds land in the bare ground matrix, with none, few or low quality resources, they might die unless they abandon it rapidly, either by flying or walking at a high speed, in search of suitable habitats ("fast patches" sensu Morales, 2002). In this habitat they adopt an extensive search behaviour (Kalushkov, 1998; Dixon, 2000), which increases their probability of encountering a fragment. In our experiments, after three hours of release very few insects were found in the matrix, while high numbers were still recaptured in alfalfa fragments (see Fig. 2). This may be explained in part by the temperature conditions in both habitats. We have recorded maximum temperatures up to $10^{\circ} \mathrm{C}$ higher in the matrix than in the alfalfa fragments (unpubl.), which could result in a higher mortality risk or in increased ladybird mobility. A positive relationship between temperatures and the frequency of long flights and walking behaviour has been described for coccinellids (Honěk, 1985; Elliott et al., 2000).

At the level of our experimental landscapes, we found that individuals significantly moved more between fragments in landscapes where fragments were close together than far apart (see Fig. 3), which has been reported before for other species of insects inhabiting fragmented landscapes (Matter, 1996; Roslin, 2000). This may be explained by the distances travelled by ladybirds on bare ground before taking flight. In this habitat very few individuals were found beyond $6 \mathrm{~m}$ of their release cell (Fig. 2). Also, additional observations of ladybird movement in the bare ground treatment indicates that while in this 
habitat many individuals could walk $2 \mathrm{~m}$ before taking flight, almost all of them flew before reaching $6 \mathrm{~m}$ (unpubl.). So, even when E. connexa does not stay for a long time on the bare ground, this habitat does represent a very important component of the landscape mosaic affecting the dispersal and distribution of these insects within the landscape (Fagan et al., 1999; Morales, 2002). Regarding fragmentation, although the literature on real landscapes suggests that more fragmented landscapes, with overall smaller patches, should promote greater rates of inter-fragment movement (Matter, 1996), in our study with 2-6 $\mathrm{m}$ distance between fragments we found no significant effect of the level of habitat fragmentation on the movement between fragments.

The higher inter-fragment movement in landscapes with fragments close together should have resulted in a higher permanence of ladybirds in these kind of landscapes. As mentioned before, individuals emigrating from a fragment would have a higher probability of intercepting another fragment of the same landscape, instead of leaving the landscape (Grez et al., 2004). On the other hand, as individuals usually remain longer in larger fragments (e.g., Mennechez et al., 2003), the permanence should have been higher in less fragmented landscapes. Nevertheless, we found a similar permanence of beetles in the landscapes, regardless of the isolation distance within the range of 2-6 m, and only a slightly higher, but non significant, permanence in landscapes with larger fragments.

The permanence of E. connexa in the different landscapes could have been influenced by aphid availability, as ladybird locomotory activity may vary depending on aphid abundance (Honěk, 1985). In our case, the permanence of ladybirds was similar in the different landscapes, and increased in March. Coincidentally, aphid abundance was similar in all landscapes, and increased in March. Nevertheless, this relationship has to be proved with dispersal experiments manipulating the availability of aphids in the landscapes. Even though aphid abundance may be related with the permanence of ladybirds in the landscape, it does not explain the higher abundance of ladybirds in the most fragmented landscapes observed in our study. Several works have noted that the aggregative responses of coccinellids are not well associated with aphid abundance, or that they respond to aphid density only at certain spatial scales (Ives et al., 1993; Elliott et al., 2002; With et al., 2002). At larger scales, other mechanisms like ladybird immigration to the landscape, reproduction and survival may have a stronger influence in determining the abundance of ladybirds (Bowman et al., 2002; Grez et al., 2004).

In summary, in this study we found that ladybird movement within fragments, in the matrix and in the boundary between both habitats may explain why ladybirds concentrate within alfalfa fragments. But their dispersal movement at the landscape level does not reflect the higher abundance, found sometimes for several species of ladybirds, in more fragmented landscapes. Studies of the relevant mechanisms acting at different spatial scales are needed to understand the dynamics of organisms in heterogeneous landscapes.

ACKNOWLEDGEMENTS. We thank B. Camousseigt, G. Cortés, S. Díaz, D. Donoso, A. Pérez, S. Reyes for their help in the field, and J. Apablaza and F. Urra for aphid sampling. F. Santibańez provided local weather information. R. Bustamante helps with statistical analyses, and L. Tischendorf, I. Hodek and three anonymous reviewers gave us very helpful advices. The Chilean government through FONDECYT 1011041 and 7011041 grants supported this research.

\section{REFERENCES}

BACH C.E. 1980: Effect of plant density and diversity on the population dynamics of a specialist herbivore, the striped cucumber beetle, Acalymna vittata (Fab.). Ecology 61: 1515-1530.

BANKS J.E. 1999: Differential response of two agroecosystem predators, Pterostichus melanarius (Coleoptera: Carabidae) and Coccinella septempunctata (Coleoptera: Coccinellidae) to habitat-composition and fragmentation-scale manipulations. Can. Entomol. 131: 645-657.

Bowman J., Cappuccino N. \& Fahrig L. 2002: Patch size and population density: the effect of immigration behavior. Conserv. Ecol. 6: 9 [Online] URL: http://www.consecol.olg/vol6/ iss $1 /$ art9.

Bullock J.M., Kenward R.E. \& Hails R.S. 2002: Dispersal Ecology. Blackwell, Oxford, UK, 443 pp.

Collinge S.K. \& Palmer T.M. 2002: The influences of patch and boundary contrast on insect response to fragmentation in California grasslands. Landsc. Ecol. 17: 647-656.

Dixon A.F.G. 2000: Insect Predator-Prey Dynamics: Ladybird Beetles and Biological Control. Cambridge University Press, Cambridge, UK, 257 pp.

Doumbia M., Hemptinne J.L. \& Dixon A.F.G. 1998: Assessment of patch quality by ladybirds: the role of larval tracks. Oecologia 113: 197-202.

Elliott N.C. \& Michels JR. G.J. 1997: Estimating aphidophagous coccinellid populations in alfalfa. Biol. Contr. 8: 43-51.

Elliott N.C., KiecKhefER R.W. \& Beck D.A. 2000: Adult coccinellid activity and predation on aphids in spring cereals. Biol. Contr. 17: 218-226.

Elliott N.C., Kieckhefer R.W., Michels Jr. G.J. \& Giles K.L. 2002: Predator abundance in alfalfa fields in relation to aphids, within field vegetation, and landscape matrix. Environ. Entomol. 31: 253-260.

Evans E.W. 2003: Searching and reproductive behaviour of female aphidophagous ladybirds (Coleoptera: Coccinellidae): a review. Eur. J. Entomol. 100: 1-10.

FAGAN W.F., CANTREL R.S. \& CosNer C. 1999: How habitat edges can change species interactions. Am. Nat. 153: $165-182$.

FAHRIG L. 2001: How much habitat is enough? Biol. Conserv. 100: $65-74$

FAHRIG L. 2003: Effects of habitat fragmentation on biodiversity. Annu. Rev. Ecol. Evol. Syst. 34: 487-515.

Grez A.A. 1997: Effect of habitat subdivision on the population dynamics of herbivorous and predatory insects in central Chile. Rev. Chil. Hist. Nat. 70: 481-490.

Grez A.A. \& Prado E. 2000: Effect of plant patch shape and surrounding vegetation on the dynamics of predatory coccinellids and their prey Brevicoryne brassicae (Hemiptera: Aphididae). Environ. Entomol. 29: 1244-1250. 
Grez A.A., Zaviezo T., Tischendorf L. \& Fahrig L. 2004: A transient, positive effect of habitat fragmentation on insect population densities. Oecologia 141: 444-451.

Hofmann W. 1970: Die Gattung Eriopis Mulsant (Col. Coccinellidae). Mitt. Münch. Entomol. Ges. 60: 102-116.

HoNĚK A. 1985: Activity and predation of Coccinella septempunctata adults in the field (Col., Coccinellidae). Z. Angew. Entomol. 100: 399-409.

IMS R.A. 1995: Movement patterns related to spatial structures. In Hansson L., Fahrig L. \& Merriam G. (eds.): Mosaic Landscapes and Ecological Processes. Chapman \& Hall, London, pp. 85-109.

Ives A.R., Kareiva P. \& Perry R. 1993: Response of a predator to variation in prey density at three hierarchical scales: ladybeetles feeding on aphids. Ecology 74: 1929-1938.

Jonsen I.D., Bourchier R.S. \& Roland J. 2001: The influence of matrix habitat on Aphthona flea beetle immigration to leafy spurge patches. Oecologia 127: 287-294.

Kalushrov P. 1998: Ten species of aphids (Sternorrhyncha: Aphididae) as prey for Adalia bipunctata (Coleoptera: Coccinellidae). Eur. J. Entomol. 95: 343-349.

Kareiva P. 1987: Habitat fragmentation and the stability of predator-prey interactions. Nature 326: 388-390.

Kareiva P. 1990: Population dynamics in spatially complex environments: theory and data. Phil. Trans. R. Soc. Lond. (B) 330: $175-190$.

Kotliar N.B. \& Wiens J.A. 1990: Multiple scales of patchiness and patch structure: a hierarchical framework for the study of heterogeneity. Oikos 59: 253-260.

MATTER S.F. 1996: Interpatch movement of the red milkweed beetle, Tetraopes tetraophthalmus: individual responses to patch size and isolation. Oecologia 105: 447-453.

Mennechez G., Schtickzelle N. \& Baguette M. 2003: Metapopulation dynamics of the bog fritillary butterfly: comparison of demographic parameters and dispersal between a continuous and a highly fragmented landscape. Landsc. Ecol. 18: $279-291$.
Morales J.M. 2002: Behavior at habitat boundaries can produce leptokurtic movement distributions. Am. Nat. 160: 531-538.

Rosuin T. 2000: Dung beetle movements at two spatial scales. Oikos 91: 323-335.

Schtickzelle N. \& Baguette M. 2003: Behavioural responses to habitat patch boundaries restrict dispersal and generate emigration-patch area relationships in fragmented landscapes. J. Anim. Ecol. 72: 533-545.

StatSoft 2000: Statistica Vol. 1: General Conventions and Statistics. StatSoft, Tulsa.

Tischendorf L., Grez A., Zaviezo T. \& Fahrig L. 2005: Mechanisms affecting population density in fragmented habitat. Ecol. Soc. 10(1): 7. [online] URL: http://www.ecologyandsociety.org/vol10/iss1/art7/

TURCHIN P. 1987: The role of aggregation in the response of Mexican bean beetles to host-plant density. Oecologia 71: 577-582.

Turchin P. 1998: Quantitative Analysis of Movement. Sinauer, Sunderland, Massachusetts, $396 \mathrm{pp}$.

Turchin P. \& Thoeny W.T. 1993: Quantifying dispersal of southern pine beetles with mark-recapture experiments and a diffusion model. Ecol. Appl. 3: 187-198.

WIENS J.A. 1992: What is landscape ecology, really? Landsc. Ecol. 7: 149-150.

Wiens J.A., Schooley R.L. \& Weeks JR. R.D. 1997: Patchy landscapes and animal movements: do beetles percolate? Oikos 78: 257-264.

WITH K.A. \& KING A.W. 1999: Dispersal success on fractal landscapes: a consequence of lacunarity thresholds. Landsc. Ecol. 14: 73-82.

With K.A., Cadaret S.J. \& Davis C. 1999: Movement responses to patch structure in experimental fractal landscapes. Ecology 80: 1340-1353.

With K.A., Pavuk D.M., Workchuck J.L., Oates R.K. \& Fisher J.L. 2002: Threshold effects of landscape structure on biological control in agroecosystems. Ecol. Appl. 12: 52-65.

Received February 17, 2004; revised and accepted January 11, 2005 